\title{
Endometriosis: alternative methods of medical
} \section{treatment}

This article was published in the following Dove Press journal:

International Journal of Women's Health

II June 2015

Number of times this article has been viewed

\section{Leticia Muñoz-Hernando' \\ Jose L Muñoz-Gonzalez' \\ Laura Marqueta-Marques' \\ Carmen Alvarez-Conejo' \\ Álvaro Tejerizo-García' \\ Gregorio Lopez-Gonzalez' \\ Emilia Villegas-Muñoz ${ }^{2}$ \\ Angel Martin-Jimenez ${ }^{3}$ \\ Jesús S Jiménez-López'}

'Endometriosis Unit, Service of Obstetrics and Gynecology, Hospital Universitario 12 de Octubre, Madrid, Spain; ${ }^{2}$ Endometriosis Unit, Service of Obstetrics and Gynecology, Hospital Carlos Haya, Malaga, Spain; ${ }^{3}$ Endometriosis Unit, Service of Obstetrics and Gynecology, Hospital Son Llatzer, Palma de Mallorca, Spain

Correspondence: Jesús S Jiménez-López Endometriosis Unit, Service of Obstetrics and Gynecology, Hospital Universitario 12 de Octubre, Avenida de Córdona s/n, E-2804I Madrid, Spain

$\mathrm{Tel}+34913908376$

Fax +34 9l 3908376

Email jjimenez.hdoc@salud.madrid.org; jjimenezme35426@gmail.com
Abstract: Endometriosis is an inflammatory estrogen-dependent disease defined by the presence of endometrial glands and stroma at extrauterine sites. The main purpose of endometriosis management is alleviating pain associated to the disease. This can be achieved surgically or medically, although in most women a combination of both treatments is required. Long-term medical treatment is usually needed in most women. Unfortunately, in most cases, pain symptoms recur between 6 months and 12 months once treatment is stopped. The authors conducted a literature search for English original articles, related to new medical treatments of endometriosis in humans, including articles published in PubMed, Medline, and the Cochrane Library. Keywords included "endometriosis" matched with "medical treatment", "new treatment", "GnRH antagonists", "Aromatase inhibitors", "selective progesterone receptor modulators", "anti-TNF $\alpha$ ”, and "antiangiogenic factors". Hormonal treatments currently available are effective in the relief of pain associated to endometriosis. Among new hormonal drugs, association to aromatase inhibitors could be effective in the treatment of women who do not respond to conventional therapies. $\mathrm{GnRH}$ antagonists are expected to be as effective as GnRH agonists, but with easier administration (oral). There is a need to find effective treatments that do not block the ovarian function. For this purpose, antiangiogenic factors could be important components of endometriosis therapy in the future. Upcoming researches and controlled clinical trials should focus on these drugs.

Keywords: pharmacological treatment options, aromatase inhibitors, GnRH antagonists, selective progesterone receptor modulators, anti-TNF- $\alpha$, endometrial tissue, antiangiogenic factors, hormonal treatments

\section{Introduction}

Endometriosis is an inflammatory estrogen-dependent disease defined by the presence of endometrial glands and stroma at extrauterine sites. It affects between $6 \%$ and $10 \%$ of women in reproductive age and causes a broad spectrum of pain symptoms ranging from no symptoms to severe dysmenorrhea, dyspareunia, dyschezia, chronic pelvic pain, and infertility. ${ }^{1}$

The main purpose of endometriosis management is alleviating pain associated to the disease. This can be achieved surgically or medically, although in most women a combination of both is required..$^{2}$ Long-term medical treatment is needed in most women; unfortunately in most women, pain symptoms recur between 6 months and 12 months once treatment is stopped.

Current medical treatments are based on two mechanisms of action: anti-inflammatory and hormonal. ${ }^{3}$ Nonsteroidal anti-inflammatory drugs (NSAIDs) are used commonly in women with dysmenorrhea, although there is not enough evidence to admit that they are effective in the treatment of endometriosis related pain, and there is lack of evidence to recommend one NSAID among the others. ${ }^{4}$

Hormonally active drugs act by blocking the ovarian function and creating a more stable hormonal environment. ${ }^{3}$ Hormonal drugs currently used for the 
treatment of pain associated to endometriosis are hormonal contraceptives, progestogens and anti-progestogens, gonadotropin releasing hormone $(\mathrm{GnRH})$ agonists and antagonists, and aromatase inhibitors. ${ }^{5}$

Hormonal contraceptives reduce pain associated to endometriosis, by oral, transdermal, or vaginal administration. ${ }^{6-8}$ Progestogens (medroxyprogesterone acetate, oral or depot, dienogest, cyproterone acetate, norethisterone acetate, danazol, levonorgestrel intrauterine device) and antiprogestogens (gestrinone) are also recommended to reduce endometriosis-associated pain. ${ }^{5-11} \mathrm{GnRH}$ agonists, with and without add-back therapy, are effective in the relief of endometriosis-associated pain, but can be associated with severe side effects. ${ }^{12}$ There is insufficient evidence to recommend one among the others, as all hormonal drugs have shown efficacy in the treatment of pain associated to endometriosis. Clinical decision should take into consideration side effects, patient preferences, efficacy, costs, and availability. ${ }^{5}$

All the drugs with proven efficacy in the treatment of pain associated to endometriosis are hormonal drugs and have a contraceptive action. Endometriosis mainly affects women in their reproductive age; hence, these treatments can be inconvenient in the case of gestational desire. There is a need for new medications, effective in the treatment of pain, with an acceptable side effects profile, suitable for long-term use, with no contraceptive effect, and safe to use in the early pregnancy.

In this paper, we present a review of current evidence in the efficacy of newer drugs used for the treatment of endometriosis, such as aromatase inhibitors, GnRH antagonists, and selective progesterone receptor modulators (SPRMs), as well as other new compounds that are under study and still not in clinical use. A brief summary of the studies discussed is tabulated in Table 1.

\section{Materials and methods}

The authors conducted a literature search for English original articles, related to new medical treatments of endometriosis in humans, including articles published in PubMed, Medline, and the Cochrane Library. Selection criteria included randomized clinical trials (RCTs), observational trials, open-label nonrandomized trials, and case reports related to medical treatments for endometriosis. The Cochrane Library was searched for reviews.

Keywords included "endometriosis", matched with "medical treatment", "new treatment", "GnRH antagonists", "Aromatase inhibitors", "selective progesterone receptor modulators", "anti-TNF $\alpha$ ", and "antiangiogenic factors".

\section{Results \\ GnRH antagonists}

The main mechanism of action of GnRH antagonists is competitive receptor occupancy of GnRH receptors; but, unlike agonists, they do not stimulate the gonadotropin release. Therefore, an immediate and reversible suppression of gonadotropin secretion is achieved. ${ }^{13}$ For these reasons, using a GnRH antagonist presumably should be as effective as using a GnRH agonist in the management of endometriosis. ${ }^{13}$ The use of injectable GnRH antagonists (cetrorelix, ganirelix) is currently approved in the context of assisted reproductive technology. ${ }^{13}$

Elagolix is an oral short-acting GnRH antagonist that, unlike injectable GnRH analogs, produces a dose-dependent suppression of pituitary and ovarian hormones in women. That is, elagolix produces partial ovarian suppression at lower doses and full suppression at higher doses. ${ }^{14}$

In a randomized, double-blind, placebo-controlled, Phase II study, ${ }^{14}$ elagolix treatment significantly improved dysmenorrhea and dyspareunia during the first 12 weeks of treatment. Elagolix showed an acceptable safety and tolerability profile in this study. Treatment-related adverse events were generally mild to moderate in severity and were consistent with the drug's mechanism of action. The most common ones (in elagolix treatment groups compared with placebo) were headache, nausea, and anxiety. Overall, the median number of hot flashes per day was slightly larger in the elagolix treatment groups. Minimal bone mineral density (BMD) changes were observed with elagolix treatment over the 24 weeks of treatment, but this reduction was lower than the changes observed after 3 months of treatment with the GnRH agonist leuprolide acetate. $^{14}$

Elagolix is a potential new strategy for achieving partial estrogen suppression in women with endometriosis-related pain, with an acceptable safety profile. However, additional, more robust studies are warranted, and presently there is no strong evidence on the efficacy of GnRH antagonists for endometriosis-associated pain. ${ }^{5}$

\section{Aromatase inhibitors}

Aromatase is a key enzyme in synthesizing estrogens from androgens, being involved in the conversion of androstenedione and testosterone to estrone and estradiol, respectively. ${ }^{15}$

Several studies suggest that aromatase is inappropriately expressed in the eutopic endometrium and ectopic endometrial implants in women with endometriosis as well as in several types of malignant tumors. ${ }^{16}$ The expression in 


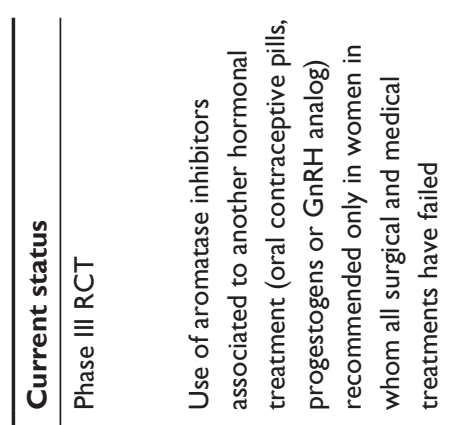

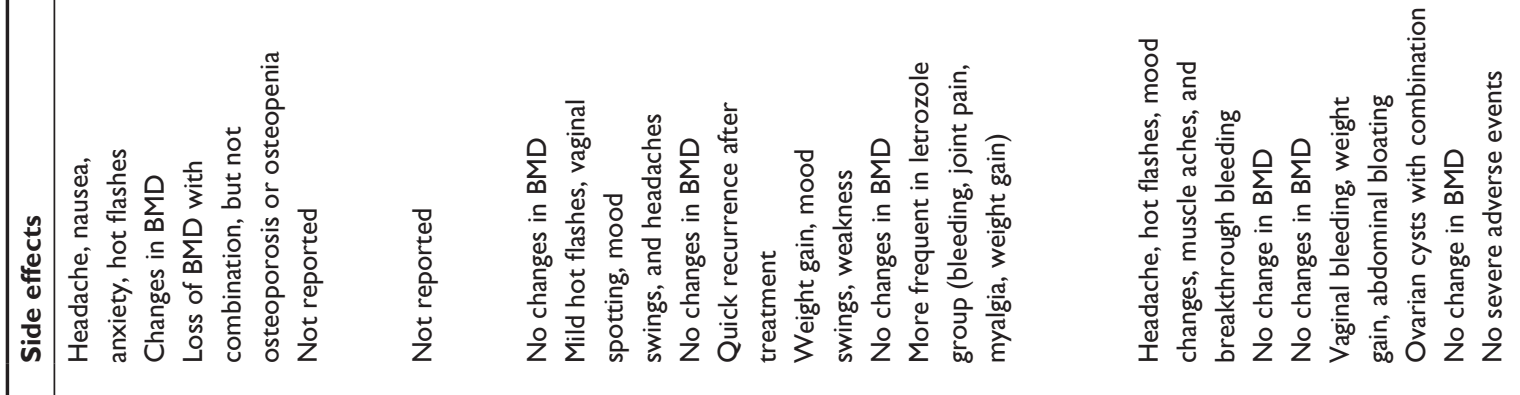
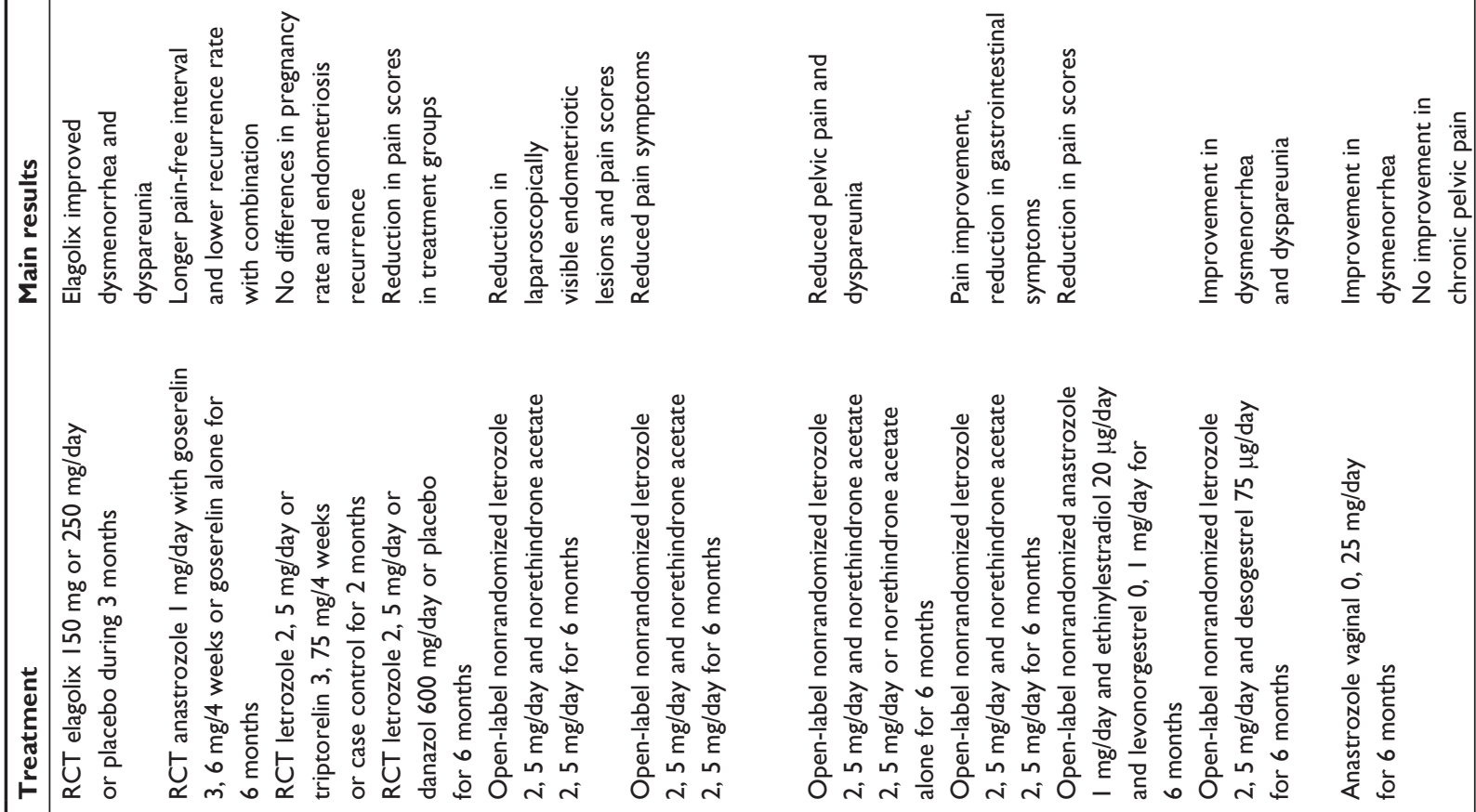

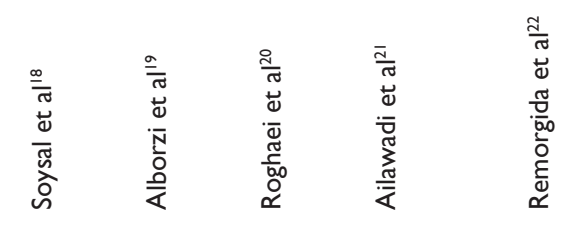

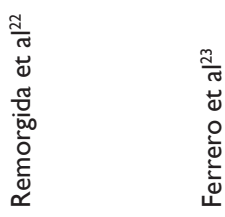

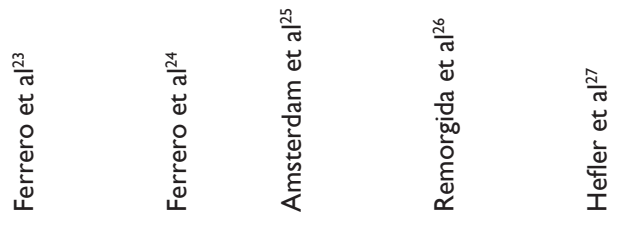
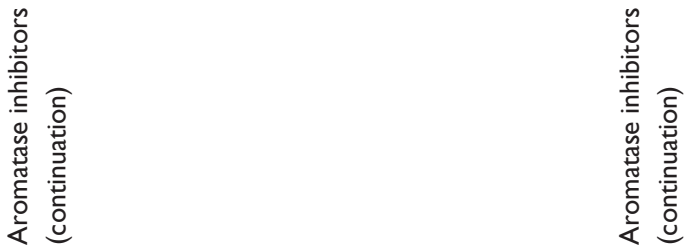


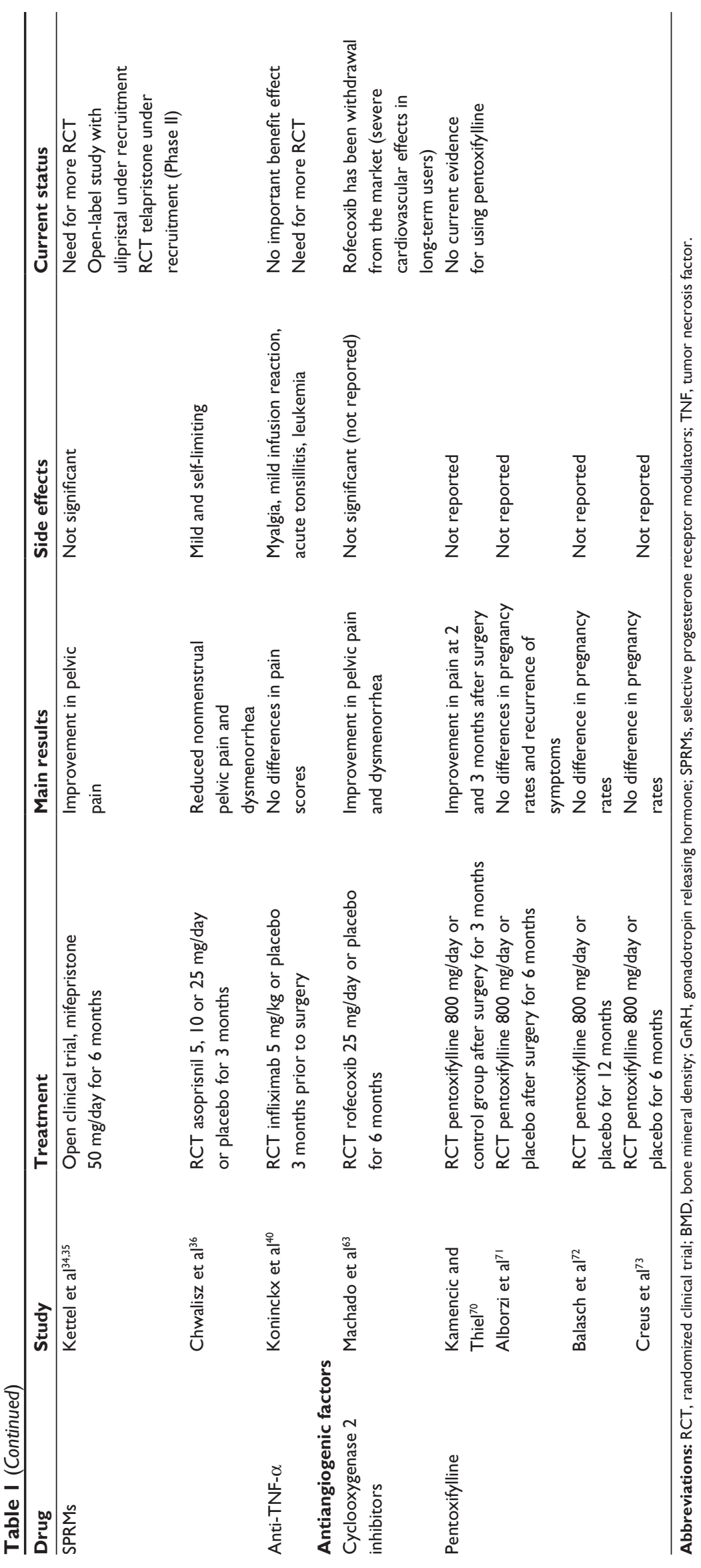


endometriotic tissue is still subject to some debate since the presence of aromatase by these tissues has not been confirmed by other studies. ${ }^{17}$

Only three RCTs are reported in literature ${ }^{18-20}$ using aromatase inhibitors in the treatment of endometriosis. The first of these studies evaluated the efficacy of using either a combination of anastrozole and goserelin for 6 months or goserelin alone for 6 months after conservative surgery for severe endometriosis. ${ }^{18}$ Treatment with anastrozole and goserelin during 6 months following surgery for severe endometriosis demonstrated longer pain-free intervals and lower symptom recurrence rates than treatment with goserelin alone.

Another RCT evaluated the role of letrozole with triptorelin versus case control on the pregnancy rate and the recurrence of symptoms and signs in patients with endometriosis. ${ }^{19}$ After treatment of 144 infertile women in their reproductive age by laparoscopy, they were divided into three groups: patients from group 1 who received letrozole for 2 months, patients from group 2 who were prescribed triptorelin for 2 months, and patients from group 3 remained as the control group. The results did not show significant differences among the three groups in pregnancy rates and endometriosis recurrence.

The third RCT published compared the impact of letrozole, danazol, and a placebo on pain scores after laparoscopic management of endometriosis. ${ }^{20}$ Mean pain scores decreased in all groups but returned to the initial levels more quickly in the placebo group when compared to the treatment group. No analysis of BMD or recurrence was carried out after the 6-month treatment period.

An open-label nonrandomized study used letrozole plus norethindrone acetate for 6 months before a second look laparoscopy, resulting in a reduction in macroscopically visible endometriosis and a relief of pain. ${ }^{21}$

Three prospective, open-label, non-randomized studies used a combination of letrozole and norethindrone acetate daily for 6 months to treat premenopausal patients with endometriosis-related pain, who were unresponsive to previous treatments such as surgery and/or GnRH agonist therapy or showed disease recurrence. ${ }^{22-24}$ The combination treatment was more effective in reducing pain, but symptoms recurred 3 months after finishing the treatment. Letrozole caused more severe side effects.

Two open-label, non-randomized studies evaluated the efficacy of aromatase inhibitors combined with oral contraceptives in premenopausal patients with endometriosis and pelvic pain unresponsive to multiple medical and surgical treatments. ${ }^{25,26}$ These treatments induced a relief of pain, but the combination of letrozole plus desogestrel induced ovarian cysts. $^{26}$

In another study without control group, anastrozole was administered intravaginally to ten patients with rectovaginal endometriosis. ${ }^{27}$ It did not show any improvement in chronic pelvic pain.

In summary, side effects most commonly associated to the treatment with aromatase inhibitors are headaches, hot flashes, mood changes, muscle aches, and breakthrough bleeding. Estradiol levels were significantly suppressed with the treatment. Significant loss of BMD was noted in the treatment with anastrozole plus goserelin, ${ }^{18}$ but no women fell into the category of osteopenia or osteoporosis. In the other studies, no significant change in BMD was reported.

The studies published do not show a clear evidence of the effectiveness of aromatase inhibitors for the treatment of pain related to endometriosis. Major limitations to their use are recurrences after finishing treatment, severe side effects, and cost. ${ }^{28}$ The European Society of Human Reproduction and Embryology (ESHRE) in their latest guideline ${ }^{5}$ recommends the use of aromatase inhibitors associated to another hormonal treatment (oral contraceptive pills, progestogens, or GnRH analogs) only in women in whom all surgical and medical treatments have failed.

\section{Selective progesterone receptor modulators}

SPRMs are defined as a new class of progesterone receptor ligands, which exhibit both progesterone agonistic and antagonistic activities. ${ }^{29}$ In the absence of progesterone, the SPRMs act like weak progestins. In the presence of progesterone, they may also show weak antiprogestagenic properties in some tissues, particularly in the endometrium. This property justifies their use in the treatment of myomas and endometriosis. Only two drugs are currently approved for gynecologic use. Mifepristone is approved for the termination of pregnancy, cervical dilation, medical termination of pregnancy during the second trimester, and fetal death in utero. ${ }^{30,31}$ Ulipristal acetate has been approved in Europe and the United States as an emergency contraceptive, and recently the European Commission has also approved ulipristal acetate for the preoperative treatment of uterine fibroids. ${ }^{32,33}$

Only two small open clinical trials have been published using mifepristone for the treatment of endometriosis. Mifepristone at $50 \mathrm{mg}$ daily dose has been shown to improve pain and cause regression of endometriosis implants, ${ }^{34}$ but at a 
lower dose is unable to control the growth of endometriosis lesions. ${ }^{35}$

A randomized placebo-controlled clinical trial using asoprisnil in the treatment of endometriosis-associated pain has been reported in an abstract form. ${ }^{36}$ Subjects with a laparoscopic diagnosis of endometriosis, exhibiting moderate or severe pain at baseline were treated with asoprisnil ( $5 \mathrm{mg}, 10 \mathrm{mg}$, and $25 \mathrm{mg}$ ) or placebo for 12 weeks. All three asoprisnil doses significantly reduced the average daily combined nonmenstrual pelvic pain/dysmenorrhea scores compared to placebo, and had a favorable safety and tolerability profile during the 3-month treatment period. There were no laboratories or clinical signs of estrogen deprivation.

Common side effects of SPRMs are headache, abdominal pain, and tenderness. They induce endometrial changes known as progesterone receptor modulator-associated endometrial changes (PAECs). The levels of estrogens are maintained, and BMD is not affected.

More number of RCTs must be developed to assess the potential benefit of SPRMs in the management of pain associated to endometriosis, and the long-term security and endometrial changes associated must be clarified. SPRMs seem to be a promising medical treatment(s) in endometriosis.

\section{Anti-tumor necrosis factor- $\alpha$}

A feature of endometriotic tissue is inflammation, which is mediated by the overproduction of prostaglandins, metalloproteinases, cytokines, and chemokines. Increased levels of acute inflammatory cytokines such as interleukin-1 $\beta$, interleukin-6, and TNF (tumor necrosis factor) are detected in the peritoneal fluid of women with endometriosis, and probably enhance the adhesion of shed endometrial-tissue fragments onto peritoneal surfaces. ${ }^{37-39}$ A nonhormonal alternative in endometriosis treatment could be modulating inflammation by means of TNF- $\alpha$ blockers as currently used in other inflammatory diseases such as Crohn's disease or rheumatoid arthritis.

A small RCT has been published using infliximab, a monoclonal anti-TNF- $\alpha$ antibody. ${ }^{40}$ Twenty-one patients with severe pain and a rectovaginal nodule were randomized to receive infliximab or placebo prior to surgery, but no differences were found in pain scores among both groups. Three adverse events were reported in the infliximab group: one case of acute tonsillitis, one case of mild infusion reaction, and one case of acute leukemia.
There is not enough evidence to recommend the use of anti-TNF- $\alpha$ drugs for the treatment of pain associated to endometriosis.

More number of blind randomized controlled trials should be developed in order to define the role of infliximab in the treatment of pain associated to endometriosis, either before or after surgery, and compare it with other medical treatments and other anti-TNF- $\alpha$ drugs. ${ }^{41}$

\section{Antiangiogenic factors}

Endometriosis is classified as an angiogenic disease. The retrograde menstruation theory ${ }^{42}$ explains pathogenesis of endometriosis due to retrograde menstruation of endometrial tissue, rich in angiogenic growth factors, which implants in the peritoneum. The endometrium from patients with endometriosis reveals a higher angiogenic activity than the endometrium from healthy women, the same as is found in endometriotic lesions and peritoneal fluid from women with endometriosis. ${ }^{43-45}$ Several studies concentrate on antiangiogenic compounds as a promising therapy for endometriosis. ${ }^{46}$

\section{Growth factor inhibitors}

One of the most studied angiogenic factors is the vascular endothelial growth factor (VEGF). The development of anti-VEGF antibody has proved in vitro efficacy in preventing the establishment of endometriotic lesions. ${ }^{47-49}$ Bevacizumab has demonstrated in vitro activity against endometriotic lesions, ${ }^{50}$ but clinical application appears to be limited because of its severe side effects, which include hypertension, proteinuria, hemorrhage and thrombosis, and gastrointestinal perforation. ${ }^{51}$

Another antiangiogenic factor, 2-methoxyestradiol, tested in studies for cancer, suppresses lesion growth with minimal toxicity. ${ }^{52,53}$ Pharmacokinetic problems due to its extensive first-pass metabolism should be resolved before new clinical trials are conducted.

The future in antiangiogenic therapy for endometriosis seems to be factors which blockade different pathways in the angiogenic cascade.

\section{Endogenous angiogenesis inhibitors}

Endostatin is an endogenous antiangiogenic factor that inhibits the development of new vessels. Some studies have shown the inhibition of developing endometriotic lesions ${ }^{49}$ without affecting fertility. ${ }^{54}$ Angiostatin, another endogenous inhibitor of angiogenesis, has been used to treat endometriotic lesions in mice but it disrupts normal ovarian function. ${ }^{55}$ 
This problem should be solved in order to advance the use of this agent.

\section{Fumagillin analog}

Fumagillin, an antibiotic produced by Aspergillus fumigatus, shows antiangiogenic activity. Some synthetic derivatives have been developed as well. Only caplostatin shows same antiangiogenic activity in endometriosis lesions but without toxic effects on the female reproductive system and neurotoxicity $;{ }^{56}$ hence, it can be candidate for future research in antiangiogenic therapy for endometriosis.

\section{Statins}

Statins, lipid-lowering drugs, have shown antiangiogenic activity in high doses. ${ }^{57}$ Studies with atorvastatin have demonstrated antiangiogenic activity in endometriotic lesions, without side effects on reproductive function. ${ }^{58,59}$ More studies are necessary to ascertain which statin is the most suitable for the antiangiogenic treatment of endometriosis and to achieve antiangiogenic activity at nontoxic doses.

\section{Cyclooxygenase 2 inhibitors}

Prostaglandin synthesis is mediated by cyclooxygenase 2 (COX-2). Its expression is increased in inflammatory and angiogenic processes. Endometriotic lesions and eutopic endometrium of patients with endometriosis show higher amounts of COX-2 when compared with controls. ${ }^{60,61}$

Studies in animals have shown that treatment with COX-2 inhibitors prevents the implantation of endometrium to ectopic sites and induces the regression of established endometriotic lesions. ${ }^{62,63}$ A randomized double-blind placebocontrolled study was carried out in 28 women using $25 \mathrm{mg}$ of rofecoxib a day during 6 months. ${ }^{64}$ The results showed more effective control of pain in the rofecoxib group than in the placebo group, with no significant side effects.

The results of in vitro studies and this clinical trial presented the COX-2 inhibitors as the ideal option for the treatment of pain associated to endometriosis. However, rofecoxib and valdecoxib have been removed from the market because of severe cardiovascular effects in long-term users. ${ }^{65}$

A study in mice compared the response in endometriotic lesions to celecoxib, anastrozole, or their combination. ${ }^{66}$ Celecoxib was the only treatment that significantly reduced the number of lesions established per mouse, lesion size, and vascularized area. In addition, cell proliferation was significantly diminished and apoptosis was significantly enhanced by both individual treatments. When the therapies were combined, their effects were reversed. These results confirm that celecoxib and anastrozole separately decrease endometriotic growth, but when combined they might have antagonizing effects.

There is currently not enough evidence to recommend the use of COX-2 inhibitors for the relief of pain in women with endometriosis, as it is not under clinical trials and for short-term treatment of severe forms of the disease.

\section{Immunomodulators: pentoxifylline}

Changes in the immune system play an essential role in the pathogenesis of endometriosis. ${ }^{67}$ For that reason, immunomodulatory agents, such as pentoxifylline, have been suggested for the treatment of endometriosis. ${ }^{68}$ Pentoxifylline has shown antiangiogenic effects in the development of endometriotic lesions in rats, ${ }^{68}$ is well tolerated, and does not inhibit ovulation. ${ }^{69}$

Some clinical trials have been published comparing the use of pentoxifylline with placebo after conservative surgery, ${ }^{70-73}$ but there was no evidence of an increase in clinical pregnancy or improvement in pain scores. Adverse events were not reported. A recent Cochrane review concluded that there is little evidence to support using pentoxifylline as a treatment for subfertility in women with endometriosis at this time. ${ }^{74}$

\section{Conclusion}

Hormonal treatments currently available are effective in the relief of pain associated to endometriosis. Treatments approved and recommended for this purpose include hormonal contraceptives (oral, transdermal, or vaginal administration), progestogens (medroxyprogesterone acetate oral or depot, dienogest, cyproterone acetate, norethindrone acetate, danazol, levonorgestrel intrauterine device) and anti-progestogens (gestrinone), and GnRH agonists.

Among new hormonal drugs, the only ones approved for use in the treatment of pain associated to endometriosis are aromatase inhibitors. They seem to be effective in the relief of pain, and their use is recommended for hormonal treatment in women who do not respond to other treatments.

GnRH antagonists are still under study, with currently active Phase III RCT. They are expected to be as effective as GnRH agonists, but with easier administration.

More number of randomized trials should be developed in order to confirm SPRMs' efficacy and long-term safety.

There is a need to find effective treatments that do not block ovarian function. New nonhormonal drugs are still 
experimental. For this purpose, antiangiogenic factors could be important components of endometriosis therapy in the future. Upcoming researches and controlled clinical trials should focus on these drugs, in order to establish if they are really effective in relieving pain without affecting fertility.

\section{Disclosure}

The authors report no conflicts of interest in this work.

\section{References}

1. Giudice LC. Clinical practice. Endometriosis. N Engl J Med. 2010; 362(25):2389-2398.

2. Johnson NP, Hummelshoj L. Consensus on current management of endometriosis. Hum Reprod. 2013;28(6):1552-1568.

3. Streuli I, de Ziegler D, Santulli P. An update on the pharmacological management of endometriosis. Expert Opin Pharmacother. 2013;14(3): 291-305.

4. Allen C, Hopewell S, Prentice A, Gregory D. Nonsteroidal antiinflammatory drugs for pain in women with endometriosis. Cochrane Database Syst Rev. 2009;2:CD004753.

5. Dunselman GA, Vermeulen N, Becker C, et al; European Society of Human Reproduction and Embryology. ESHRE guideline: management of women with endometriosis. Hum Reprod. 2014;29(3):400-412.

6. Vercellini P, Trespidi L, Colombo A, Vendola N, Marchini M, Crosignani PG. A gonadotropin-releasing hormone agonist versus a lowdose oral contraceptive for pelvic pain associated with endometriosis. Fertil Steril. 1993;60:75-79.

7. Davis LJ, Kennedy SS, Moore J, Prentice A. Oral contraceptives for pain associated with endometriosis. Cochrane Database Syst Rev. 2007; 3:CD001019.

8. Vercellini P, Barbara G, Somigliana E, Bianchi S, Abbiati A, Fedele L. Comparison of contraceptive ring and patch for the treatment of symptomatic endometriosis. Fertil Steril. 2010;93:2150-2161.

9. Abou-Setta AM, Houston B, Al-Inany HG, Farquhar C. Levonorgestrelreleasing intrauterine device (LNG-IUD) for symptomatic endometriosis following surgery. Cochrane Database Syst Rev. 2013;1:CD005072.

10. Farquhar C, Prentice A, Singla AA, Selak V. Danazol for pelvic pain associated with endometriosis. Cochrane Database Syst Rev. 2007;4: CD000068.

11. Brown J, Kives S, Akhtar M. Progestagens and anti-progestagens for pain associated with endometriosis. Cochrane Database Syst Rev. 2012; 3:CD002122.

12. Brown J, Pan A, Hart RJ. Gonadotrophin-releasing hormone analogues for pain associated with endometriosis. Cochrane Database Syst Rev. 2010;12:CD008475.

13. Huirne JA, Lambalk CB. Gonadotropin-releasing-hormone-receptor antagonists. Lancet. 2001;358(9295):1793-1803.

14. Diamond MP, Carr B, Dmowski WP, et al. Elagolix treatment for endometriosis-associated pain: results from a phase 2, randomized, double-blind, placebo-controlled study. Reprod Sci. 2014;21:363-371.

15. Simpson ER, Mahendroo MS, Means GD, et al. Aromatase cytochrome P450, the enzyme responsible for estrogen biosynthesis. Endocr Rev. 1994; 15:342-355.

16. Bulun SE, Sharda G, Rink J, Sharma S, Simpson ER. Distribution of aromatase P450 transcripts and adipose fibroblasts in the human breast. J Clin Endocrinol Metab. 1996;81:1273-1277.

17. Colette S, Lousse JC, Defrère S, et al. Absence of aromatase protein and mRNA expression in endometriosis. Hum Reprod. 2009;24: 2133-2141.

18. Soysal S, Soysal ME, Ozer S, Gul N, Gezgin T. The effects of postsurgical administration of goserelin plus anastrozole compared to goserelin alone in patients with severe endometriosis: a prospective randomized trial. Hum Reprod. 2004;19:160-167.
19. Alborzi S, Hamedi B, Omidvar A, Dehbashi S, Alborzi S, Alborzi M. A comparison of the effect of short-term aromatase inhibitor (letrozole) and GnRH agonist (triptorelin) versus case control on pregnancy rate and symptom and sign recurrence after laparoscopic treatment of endometriosis. Arch Gynecol Obstet. 2011;284:105-110.

20. Roghaei MA, Tehrany HG, Taherian A, Koleini N. Effects of letrozole compared with danazol on patients with confirmed endometriosis: a randomized clinical trial. Int J Fertili Steril. 2010;4:67-72.

21. Ailawadi RK, Jobanputra S, Kataria M, Gurates B, Bulun SE. Treatment of endometriosis and chronic pelvic pain with letrozole and norethindrone acetate: a pilot study. Fertil Steril. 2004;81:290-296.

22. Remorgida V, Abbamonte HL, Ragni N, Fulcheri E, Ferrero S. Letrozole and norethisterone acetate in rectovaginal endometriosis. Fertil Steril. 2007; 88:724-726.

23. Ferrero S, Camerini G, Seracchioli R, Ragni N, Venturini PL, Remorgida V. Letrozole combined with norethisterone acetate compared with norethisterone acetate alone in the treatment of pain symptoms caused by endometriosis. Hum Reprod. 2009;24:3033-3041.

24. Ferrero S, Camerini G, Ragni N, et al. Letrozole and norethisterone acetate in colorectal endometriosis. Eur J Obstet Gynecol Reprod Biol. 2010;150:199-202.

25. Amsterdam LL, Gentry W, Jobanputra S, Wolf M, Rubin SD, Bulun SE. Anastrazole and oral contraceptives: a novel treatment for endometriosis. Fertil Steril. 2005;84:300-304.

26. Remorgida V, Abbamonte LH, Ragni N, Fulcheri E, Ferrero S. Letrozole and desogestrel-only contraceptive pill for the treatment of stage IV endometriosis. Aust N Z J Obstet Gynaecol. 2007;47:222-225.

27. Hefler LA, Grimm C, van Trotsenburg M, Nagele F. Role of the vaginally administered aromatase inhibitor anastrozole in women with rectovaginal endometriosis: a pilot study. Fertil Steril. 2005;84:1033-1036.

28. Colette S, Donnez J. Are aromatase inhibitors effective in endometriosis treatment? Expert Opin Investig Drugs. 2011;20(7):917-931.

29. Chwalisz K, Garg R, Brenner RM, Schubert G, Elger W. Selective progesterone receptor modulators (SPRMs): a novel therapeutic concept in endometriosis. Ann N Y Acad Sci. 2002;955:373-388.

30. Schaff EA. Mifepristone: ten years later. Contraception. 2010;81: $1-7$.

31. Im A, Appleman LJ. Mifepristone: pharmacology and clinical impact in reproductive medicine, endocrinology and oncology. Expert Opin Pharmacother. 2010;11:481-488.

32. Donnez J, Tatarchuk TF, Bouchard P, et al; PEARL I Study Group. Ulipristal acetate versus placebo for fibroid treatment before surgery. N Engl J Med. 2012;366:409-420.

33. Donnez J, Tomaszewski J, Vázquez F, et al; PEARL II Study Group. Ulipristal acetate versus leuprolide acetate for uterine fibroids. $N \mathrm{Engl}$ J Med. 2012;366:421-432.

34. Kettel LM, Murphy AA, Morales AJ, Ulmann A, Baulieu EE, Yen SS. Treatment of endometriosis with the antiprogesterone mifepristone (RU486). Fertil Steril. 1996;65:23-28.

35. Kettel LM, Murphy AA, Morales AJ, Yen SS. Preliminary report on the treatment of endometriosis with low-dose mifepristone (RU 486). Am J Obstet Gynecol. 1998;178:1151-1156.

36. Chwalisz K, Mattia-Goldberg C, Elger W, Edmonds A. Treatment of endometriosis with the novel selective progesterone receptor modulator (SPRM) asoprisnil. Fertil Steril. 2004;82:S83-S84.

37. Bulun SE. Mechanism of disease. Endometriosis. N Engl J Med. 2009; 360:268-279.

38. Tseng JF, Ryan IP, Milam TD, et al. Interleukin-6 secretion in vitro is upregulated in ectopic and eutopic endometrial stromal cells from women with endometriosis. J Clin Endocrinol Metab. 1996;81:1118-1122.

39. Hornung D, Ryan IP, Chao VA, Vigne JL, Schriock ED, Taylor RN. Immunolocalization and regulation of the chemokine RANTES in human endometrial and endometriosis tissues and cells. $J$ Clin Endocrinol Metab. 1997;82:1621-1628.

40. Koninckx PR, Craessaerts M, Timmerman D, Cornillie F, Kennedy S. Anti-TNF-alpha treatment for deep endometriosis-associated pain: a randomized placebo-controlled trial. Hum Reprod. 2008;23(9): 2017-2023. 
41. Lu D, Song H, Shi G. Anti-TNF- $\alpha$ treatment for pelvic pain associated with endometriosis. Cochrane Database Syst Rev. 2013;3: CD008088.

42. Sampson JA. Peritoneal endometriosis due to menstrual dissemination of endometrial tissue into the peritoneal cavity. Am J Obstet Gynecol. 1927; 14:422-469.

43. Groothuis PG, Nap AW, Winterhager E, Grümmer R. Vascular development in endometriosis. Angiogenesis. 2005;8:147-156.

44. Laschke MW, Menger MD. In vitro and in vivo approaches to study angiogenesis in the pathophysiology and therapy of endometriosis. Hum Reprod Update. 2007;13:331-342.

45. Hur SE, Lee JY, Moon HS, Chung HW. Angiopoietin-1, angiopoietin-2 and Tie-2 expression in eutopic endometrium in advanced endometriosis. Mol Hum Reprod. 2006;12:421-426.

46. Laschke MW, Menger MD. Anti-angiogenic treatment strategies for the therapy of endometriosis. Hum Reprod Update. 2012;18:682-702.

47. Hull ML, Charnock-Jones DS, Chan CL, et al. Antiangiogenic agents are effective inhibitors of endometriosis. J Clin Endocrinol Metab. 2003; 88:2889-2899.

48. Nap AW, Griffioen AW, Dunselman GA, et al. Antiangiogenesis therapy for endometriosis. J Clin Endocrinol Metab. 2004;89:1089-1095.

49. Nap AW, Dunselman GA, Griffioen AW, Mayo KH, Evers JL, Groothuis PG. Angiostatic agents prevent the development of endometriosis-like lesions in the chicken chorioallantoic membrane. Fertil Steril. 2005;83:793-795.

50. Ricci AG, Olivares CN, Bilotas MA, Meresman GF, Barañao RI. Effect of vascular endothelial growth factor inhibition on endometrial implant development in a murine model of endometriosis. Reprod Sci. 2011;18: 614-622.

51. Kamba T, McDonald DM. Mechanisms of adverse effects of anti-VEGF therapy for cancer. Br J Cancer. 2007;96:1788-1795.

52. Dahut WL, Lakhani NJ, Gulley JL, et al. Phase I clinical trial of oral 2-methoxyestradiol, an antiangiogenic and apoptotic agent, in patients with solid tumors. Cancer Biol Ther. 2006;5:22-27.

53. Kulke MH, Chan JA, Meyerhardt JA, et al. A prospective phase II study of 2-methoxyestradiol administered in combination with bevacizumab in patients with metastatic carcinoid tumors. Cancer Chemother Pharmacol. 2011;68:293-300.

54. Becker CM, Sampson DA, Rupnick MA, et al. Endostatin inhibits the growth of endometriotic lesions but does not affect fertility. Fertil Steril. 2005;84(suppl 2):1144-1155.

55. Dabrosin C, Gyorffy S, Margetts P, Ross C, Gauldie J. Therapeutic effect of angiostatin gene transfer in a murine model of endometriosis. Am J Pathol. 2002;161:909-918.

56. Satchi-Fainaro R, Puder M, Davies JW, et al. Targeting angiogenesis with a conjugate of HPMA copolymer and TNP-470. Nat Med. 2004;10:255-261.

57. Dulak J, Jozkowicz A. Anti-angiogenic and anti-inflammatory effects of statins: relevance to anti-cancer therapy. Curr Cancer Drug Targets. 2005;5:579-594.

58. Oktem M, Esinler I, Eroglu D, Haberal N, Bayraktar N, Zeyneloglu HB. High-dose atorvastatin causes regression of endometriotic implants: a rat model. Hum Reprod. 2007;22:1474-1480.
59. Bruner-Tran KL, Osteen KG, Duleba AJ. Simvastatin protects against the development of endometriosis in a nude mouse model. J Clin Endocrinol Metab. 2009;94:2489-2494.

60. Ota H, Igarashi S, Sasaki M, Tanaka T. Distribution of cyclooxygenase-2 in eutopic and ectopic endometrium in endometriosis and adenomyosis. Hum Reprod. 2001;16:561-566.

61. Cho S, Park SH, Choi YS, et al. Expression of cyclooxygenase-2 in eutopic endometrium and ovarian endometriotic tissue in women with severe endometriosis. Gynecol Obstet Invest. 2010;69:93-100.

62. Olivares C, Ricci A, Bilotas M, Barañao RI, Meresman G. The inhibitory effect of celecoxib and rosiglitazone on experimental endometriosis. Fertil Steril. 2011;96:428-433.

63. Machado DE, Berardo PT, Landgraf RG, et al. A selective cyclooxygenase-2 inhibitor suppresses the growth of endometriosis with an antiangiogenic effect in a rat model. Fertil Steril. 2010;93: 2674-2679.

64. Cobellis L, Razzi S, De Simone S, et al. The treatment with a COX-2 specific inhibitor is effective in the management of pain related to endometriosis. Eur J Obstet Gynecol Reprod Biol. 2004;116:100-102.

65. Burnier M. The safety of rofecoxib. Expert Opin Drug Saf. 2005;4(3): 491-499.

66. Olivares CN, Bilotas MA, Ricci AG, Barañao RI, Meresman GF. Anastrozole and celecoxib for endometriosis treatment, good to keep them apart? Reproduction. 2013;145(2):119-126.

67. Dmowski WP, Braun DP. Immunology of endometriosis. Best Pract Res Clin Obstet Gynaecol. 2004;18:245-263.

68. Vlahos NF, Gregoriou O, Deliveliotou A, et al. Effect of pentoxifylline on vascular endothelial growth factor $\mathrm{C}$ and flk-1 expression on endometrial implants in the rat endometriosis model. Fertil Steril. 2010;93:1316-1323.

69. Olive DL, Lindheim SR, Pritts EA. New medical treatments for endometriosis. Best Pract Res Clin Obstet Gynaecol. 2004;18:319-328.

70. Kamencic H, Thiel JA. Pentoxifylline after conservative surgery for endometriosis: a randomized, controlled trial. J Minim Invasive Gynecol. 2008;15:62-66.

71. Alborzi S, Ghotbi S, Parsanezhad ME, Dehbashi S, Alborzi S, Alborzi M. Pentoxifylline therapy after laparoscopic surgery for different stages of endometriosis: a prospective, double-blind, randomized, placebocontrolled study. J Minim Invasive Gynecol. 2007;14(1):54-58.

72. Balasch J, Creus M, Fabregues F, et al. Pentoxifylline versus placebo in the treatment of infertility associated with minimal or mild endometriosis: a pilot randomized clinical trial. Hum Reprod. 1997;12(9): 2046-2050.

73. Creus M, Fabregues F, Carmona F, Del Pino M, Manau D, Balasch J. Combined laparoscopic surgery and pentoxifylline therapy for treatment of endometriosis-associated infertility: a preliminary trial. Hum Reprod. 2008;23(8):1910-1916.

74. Lu D, Song H, Li Y, Clarke J, Shi G. Pentoxifylline for endometriosis Cochrane Database Syst Rev. 2012;1:CD007677.
International Journal of Women's Health

\section{Publish your work in this journal}

The International Journal of Women's Health is an international, peerreviewed open-access journal publishing original research, reports, editorials, reviews and commentaries on all aspects of women's healthcare including gynecology, obstetrics, and breast cancer. The manuscript management system is completely online and includes

\section{Dovepress}

a very quick and fair peer-review system, which is all easy to use. Visit http://www.dovepress.com/testimonials.php to read real quotes from published authors. 